Journal of Polymer Science and Engineering (2018) Volume 1 doi:10.24294/jpse.v1i3.723

\title{
Polyblends and Composites of Poly (Lactic Acid) (PLA): A Review on the State of the Art
}

\author{
Krishna Prasad Rajan ${ }^{1 *}$,Selvin P. Thomas ${ }^{1,2}$, Aravinthan Gopanna ${ }^{2}$, Ahmed Al-Ghamdi ${ }^{1}$,Murthy \\ Chavali $^{3}$ \\ ${ }^{1}$ Royal Commission Yanbu Colleges \& Institutes, Yanbu Industrial College, Department of Chemical Engineering \\ Technology,PO Box: 30436, Yanbu Industrial City 41912 Kingdom of Saudi Arabia. E-mail: rajank@rcyci.edu.sa \\ ${ }^{2}$ Advanced Materials Laboratory, Yanbu Research Center, Royal Commission YanbuColleges and Institutes, P. O. Box \\ 30436, Yanbu Industrial City41912, Kingdom of Saudi Arabia \\ ${ }^{3}$ MCETRC, Tenali, Guntur 522201 Andhra Pradesh, India
}

\begin{abstract}
Polymers obtained from renewable sources are gaining popularity over their petroleum based counterparts in recent years due to their capability to address the environmental pollution related concerns emanating from the widespread usage of synthetic polymers. Even though the polymers from renewable sources are attractive in an environmental point of view, some of the property limitations and the high cost of these materials pose limitations for their extensive commercial applications. These aspects opened the door for a large chunk of research activities in development of polyblends and composites containing polymers from renewable sources as one of the components. Poly (lactic acid) (PLA) is one of the most discussed and commercialized polymer originated from renewable resources. Even though it has many useful properties, certain disadvantages like high brittleness, low impact resistance etc. limit the wide spread commercialization of PLA. In this review article, the recent research activities which are aimed to fill this gap by various modifications of PLA are discussed with special emphasis on the latest research advancements in the field of biodegradable and non biodegradable systemscontaining PLA.
\end{abstract}

Keywords: Poly (lactic acid); Polyblends; Composites; Modifications

\section{Introduction}

Poly (lactic acid) (PLA) is a biodegradable biopolymer produced from natural resources. It is considered as one of the most promising bio-based polymers and hence attracted the interest of researchers over the last two decades. Figure 1 shows the tremendous increase in publications reported on PLA since year 1996.

The research on PLA is truly interdisciplinary in nature with the involvement of all branches of science and technology. Scarcely an area is untouched. Figure 2 shows the distribution of reported literatures in figure 1 into various subject areas.

PLA belongs to the family of aliphatic polyesters, for which the starting materials are a -hydroxy acids. The main feedstock for PLA synthesis is lactic acid. The commercial production of lactic acid started in Japan during $1950^{[1]}$. Chemically, lactic acid is 2-hydroxypropanoic acid. Due to the presence of a chiral carbon atom in its structure, it exists in two enantiomeric forms,widely known as L-lactic acid and D-lactic acid (Figure 3).

Majority of the lactic acid available in the market today is produced by bacterial fermentation of carbohydrates such as corn, sugarcane, or tapioca ${ }^{[2]}$. Other carbohydrate feedstock for the production of lactic acid includes cassava starch, lignocellulose/hemicellulose hydrolysates,cottonseed hulls, corn cobs, corn stalks, beetmolasses, wheat bran, rye flour, sweet sorghum, sugarcane pressmud, cassava, barley starch, cellulose, carrot processing waste, molassesspent wash, corn fiber hydrolysates, and potato $\operatorname{starch}^{[3]}$. Abdel-Rahman et al, reviewed the recent developments of fermentation processes for lactic acid production $^{[4]}$. 
PLA can be synthesized from lactic acid by polycondensation of lactic acid or ring-opening polymerization of lactide. The stereo chemical structure, molecular weight and crystallinity of the resulting polymer can easily be controlled by polymerizing a mixture of 1 and $d$ isomers of lactic acid. Large number of literatures is available describing the synthesis of PLA from lactic $\operatorname{acid}^{[5-12]}$. The major producers of PLA include NatureWorks ${ }^{\circledR}$ LLC, Mitsui Chemicals, Dai Nippon Printing Co., Shimadzu,NEC, Toyobo, Toyota (Japan), PURAC Biomaterials, Hycail (The Netherlands), Galactic (Belgium), Cereplast (U.S.A.), FkuR, Stanelco, Biomer, Inventa-Fischer (Germany), and Snamprogetti (China) ${ }^{[13]}$. PLA can be processed by conventional plastic processing techniques such as injection molding, extrusion, blow molding, thermoforming, foaming and fiber spinning process into various articles. In addition to its biodegradability and biocompatibility, PLA exhibits good transparency and processability, which makes it a versatile polymer for several commercial as well as medical applications ${ }^{[10]}$. PLA exhibits major functional properties such as, high gloss and clarity, crimp (ability to hold a crease or fold), low temperature heat seal, low coefficient of friction and resistance to oils, which makes it a suitable candidate for packaging applications ${ }^{[14]}$. Other applications include automotive interiors, consumer electronics, sportswear, boots, coffee cups and lids, game consoles and personal protection equipments.The properties of some of the commercial grades of Corbion PLA are summarized in Table $\mathbf{1 .}$

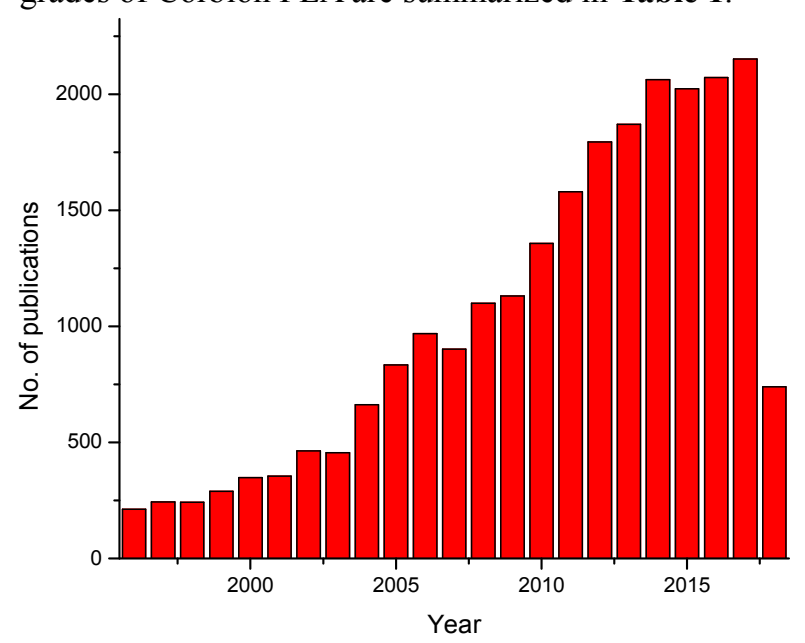

Figure 1; Number of articles published since 1996 based on Scopus search (accessed on $13^{\text {th }}$ April 2018) using keyword



Figure 2; Distribution of reported publications in figure 1 into various fields of research (source: scopus, accessed on $13^{\text {th }}$ April, 2018).<smiles>C[C@H](O)C(=O)O</smiles><smiles>C[C@H](O)C(=O)O</smiles>

L-(+)-Lactic acid

D-(-)-Lactic acid

Figure 3; Isomers of Lactic acid (L-lactic acid and D-Lactic acid).

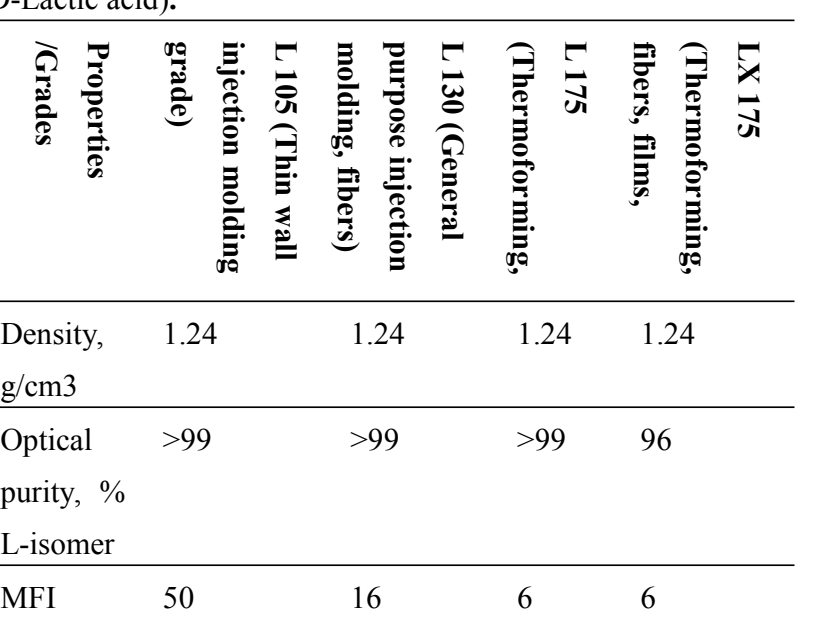

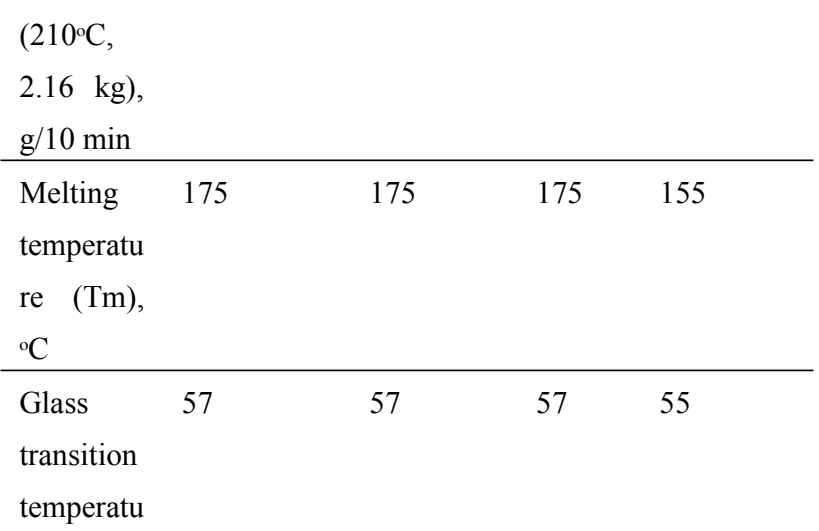




\begin{tabular}{|c|c|c|c|c|}
\hline $\begin{array}{l}\text { re }(\mathrm{Tm}), \\
{ }^{\circ} \mathrm{C}\end{array}$ & & & & \\
\hline $\begin{array}{l}\text { Tensile } \\
\text { modulus, } \\
\mathrm{MPa}\end{array}$ & 3500 & 3500 & 3500 & 3500 \\
\hline $\begin{array}{l}\text { Tensile } \\
\text { strength, } \\
\mathrm{MPa}\end{array}$ & 50 & 50 & 50 & 45 \\
\hline $\begin{array}{l}\text { Elongatio } \\
\mathrm{n} \\
\text { at break, } \\
\%\end{array}$ & $<5$ & $<5$ & $<5$ & $<5$ \\
\hline $\begin{array}{l}\text { Charpy } \\
\text { impact } \\
\text { strength, } \\
\mathrm{kJ} / \mathrm{m}^{2}\end{array}$ & $<5$ & $<5$ & $<5$ & $<5$ \\
\hline $\begin{array}{l}\text { HDT B } \\
\text { (amorpho } \\
\text { us) }{ }^{\circ} \mathrm{C}\end{array}$ & $55-60$ & $55-60$ & $55-60$ & $55-60$ \\
\hline $\begin{array}{l}\text { HDT B } \\
\text { (crystalli } \\
\text { ne) }{ }^{\circ} \mathrm{C}\end{array}$ & $100-110$ & $100-110$ & $\begin{array}{l}100-1 \\
10\end{array}$ & - \\
\hline
\end{tabular}

Table 1. Properties of Corbion PLA grades (Source: http://www.corbion.com)

\section{Modifications of PLA}

Even though PLA exhibits several useful properties, its brittleness, susceptibility to hydrolysis, low impact resistance and low elongation at break are some of the limiting factors for widespread commercial application of this material. In order to overcome these deficiencies, several methods were developed by various researchers in this field and some of them are: i) blending with plasticizers, ii) copolymerization, iii) blending with other polymers, iv) preparing nanocomposites and v) surface modifications ${ }^{[15]}$. Preparation of blends and composites of PLA as a performance improvement technique for PLAis reviewed in detail in this article, with more emphasis on the recent developments.

\section{Blends and composites of PLA with polyolefins}

The blending of PLA with polyolefins is carried out by several researchers as a method to improve the resistance to hydrolysis and biodegradation, and also to toughen PLA. But the main barrier in blending polyolefins with PLA is the formation of an immiscible blend due to the lack of chemical interactions between the blend components. Wang et al ${ }^{[16]}$ prepared solution blend of LDPE and PLA using a diblock copolymer (PE-b-PLLA) as the compatibilizer. The particle size and distribution of the dispersed phase (LDPE) was observed to decrease sharply and the mechanical properties were significantly improved with the incorporation of the diblock copolymer. Andersonet $a l^{[17]}$ carried out melt blending of linear low-densitypolyethylene (LLDPE) with PLA. Polylactide-polyethylene (PLLA-PE) block copolymers were used as compatibilizers for the blend. Young et al. ${ }^{[18]}$ used PE-g-GMA as a reactive compatibilizer for the immiscible blend system consisting of LLDPE and PLA. For PLA matrix blends, the reactive compatibilizer reduced the domain size of thedispersed phase (LLDPE) and enhanced the tensile properties of the blend. In an attempt to improve the dyeability and resistance to biodegradation and hydrolysis of PLA, Reddy et al ${ }^{[19]}$ prepared polyblendfibres of PP and PLA. Polypropylene-graft-poly(methylmethacrylate)(PP-g-PM MA) graft copolymers were synthesised as effective compatibilizers for PP/PLA blends by Kaneko et al ${ }^{[20]}$. Tensile and flexural strength and modulus of the PP/PLA blends were significantly improved by adding PP-g-PMMA, whereas, the compatibilizer could not succeed in improving the izod impact strength and elongation at break of the blends. Choudhary et al.also used Maleic anhydride grafted PP (MAH-g-PP) and glycidyl methacrylate in PLA/PP blends as reactive compatibilizers $^{[21]}$. Recently, ZuzannaDonnelly patented the technology related to the blends of PLA with polyolefines ${ }^{[22]}$. Hong et $a l^{[23]}$ patented the process for thepreparation of eco-friendly PP/PLA composite composition containing a compatibilizer. Rheological and mechanical properties of PP/PLA blends were characterised by Hamad et $a l^{[24]}$. The rheological measurements showed that the true viscosity of the blends was in between the viscosity of neat PP and PLA, whereas, the mechanical properties clearly indicated the incompatibility between PP and PLA.

Polyblends of PP and PLA in the ratio 80:20 were prepared by Yoo et al. ${ }^{[25]}$ Polypropylene-g-maleic 
anhydride

(PP-g-MAH).

And

styrene-ethylene-butylene-styrene-g-maleic anhydride (SEBS-g-MAH) were used as compatibilizers. It was reported that at $3 \mathrm{wt} \%$ of PP-g-MAH content, the tensile strength reached a maximum value and the tensile strength did not change appreciably even after hydrolysis. Ternary blends of PP, PLA and a toughening modifier in the ratio $60: 30: 10$ were prepared by Lee et al. ${ }^{[26]}$ PP-g-MAH and polyethylene-g- glycidyl methacrylate (PE-g-GMA). And a hybrid compatibilizer composed of these two were incorporated into the ternary blends in various ratios. It was reported that $3 \mathrm{wt} \%$ of the hybrid compatibilizer enhanced the mechanical properties of the ternary blend before and after hydrolysis. Recently, the effectiveness of ethylene-glycidyl methacrylate-methyl acrylate terpolymer(PEGMMA) as a reactive compatibilizer for PLA and PP blends (in the ratio 90:10) was reported by $\mathrm{Xu}$ et al. ${ }^{[27]}$. This compatibilization strategy resulted in reduced interfacial tension, enhancement of tensile toughness and elongation at break of the resulting polyblend system. The isothermal crystallisation process of PLA and PP blends with and without MA-g-PP was studied by Bai et al. ${ }^{[28]}$. It was shown that blending PLA with PP resulted in a reduction in the size of spherulites and the presence of MA-g-PP in blends of PLA with PP promoted the growth of spherulites during the crystallisation process. The effect of ethylene-butyl acrylate glycidyl methacrylate terpolymer (EBA-GMA) as a compatibilizer for 70:30 blend of PLA and PP was investigated by Kang et al. ${ }^{[29]}$. Based on the mechanical properties, it was shown that at $2.5 \mathrm{wt} \%$ of EBA-GMA, the tensile strength of the blend reached a maximum, whereas, the impact strength showed a steady increase with anincrease in compatibilizer content.

Kim et $a l .{ }^{[30]}$ prepared natural-flour-filled PP/PLA bio-composites. Bamboo flour and wood flour were used as the reinforcing filler. Modifications of these natural flours were carried out by treating them with maleic anhydride-grafted PP and acrylic acid-grafted PP. Tensile and flexural strengths of biocomposites were found to improve as a result of the modification. In a similar investigation, oat hull fibre was used as reinforcement for PP/PLA based biocomposites by
Reddy et $a l .^{[31]}$ They have prepared a PP/PLA $(90 / 10)$ blend reinforced with $30 \mathrm{wt} \%$ oat hull and investigated the effect of ethylene propylene-g-maleic anhydride (EP-g-Ma) as a compatibilizer for this biocomposite. Nunez et al. ${ }^{[32]}$ prepared PLA/PP blends compatibilized by four different grafted polymers and subsequently prepared their nanocomposites with Sepiolite. The blend containing grafted metallocene polyethylene as the compatibilizer exhibited the highest tensile toughness. The incorporation of Sepiolite into the compatibilized blend resulted in an improvement in mechanical properties, complex viscosity and storage modulus compared with similar nanocomposites containing only PLA as the matrix. Gallego et al synthesised three random copolymers of PLA and PE and studied their effectiveness as compatibilizers for PLA-HDPE blends ${ }^{[33]}$. The compatibilizers were prepared by three different methods: reactive extrusion, ring-opening polymerization and polycondensation of lactide with PE. The PLA-HDPE blends containing the compatibilizer prepared by ring opening polymerization of lactide with PE exhibited the highest tensile toughness. Light weight semicrystalline micro cellular plastics based on PLA/polylefin hybrids by cold drawing technique were prepared by $\mathrm{Xu}$ et al. ${ }^{[34]}$. Rheological studies, morphological investigations using scanning electron microscopy (SEM) and transmission electron microscopy (TEM) and wide angle $\mathrm{x}$-ray scattering (WAXS) techniques along with theoretical models were used by Aghjeh et $a l^{[35]}$ to quantitatively assess the microstructure of PLA/PP/organoclay nanocomposites. The investigations also revealed that the organoclay has a tendency to localize near the PLA phase. Some recent developments in the blends and composites of PLA with polyolefins, especially with PP are given in Table 2. 


\begin{tabular}{|c|c|c|c|}
\hline $\begin{array}{l}\text { S. } \\
\text { No. }\end{array}$ & Description of the investigation & Result & Reference \\
\hline 1. & $\begin{array}{l}\text { Preparation of polyblend fibres of PP and } \\
\text { PLA. }\end{array}$ & $\begin{array}{l}\text { The inclusion of PP to PLA resulted in an } \\
\text { improvement in the dyeability and resistance } \\
\text { to biodegradation and hydrolysis of PLA. }\end{array}$ & Reddy et al. ${ }^{[19]}$ \\
\hline 2. & $\begin{array}{l}\text { Polypropylene-graft-poly (methyl } \\
\text { methacrylate) (PP-g-PMMA) graft } \\
\text { copolymers as effective compatibilizers for } \\
\text { PP/PLA blends }\end{array}$ & $\begin{array}{l}\text { Tensile and flexural strength and modulus of the } \\
\text { PP/PLA blends were significantly improved by adding } \\
\text { PP-g-PMMA, whereas, the compatibilizer could not } \\
\text { succeed in improving the Izod impact strength and } \\
\text { elongation at break of the blends. }\end{array}$ & Kaneko et al. ${ }^{[20]}$. \\
\hline 3. & $\begin{array}{l}\text { Maleic anhydride grafted PP (MAH-g-PP) } \\
\text { and glycidyl methacrylate in } \\
\text { PLA/PP blends as reactive compatibilizers }\end{array}$ & Improved the compatibility between PP and PLA & $\begin{array}{l}\text { Choudhary et } \\
\text { al. } .^{[21]} \text {. }\end{array}$ \\
\hline 4. & $\begin{array}{l}\text { The technology related to the blends of } \\
\text { PLA with polyolefines }\end{array}$ & Patent & $\begin{array}{l}\text { Zuzanna } \\
\text { Donnelly }{ }^{[22]} \text {. }\end{array}$ \\
\hline 5. & $\begin{array}{l}\text { The process for the preparation of } \\
\text { eco-friendly PP/PLA composite } \\
\text { composition containing a compatibilizer. }\end{array}$ & Patent & Hong et $a l^{[23]}$ \\
\hline 6. & $\begin{array}{l}\text { Characterization of rheological and } \\
\text { mechanical properties of PP/PLA blends. }\end{array}$ & $\begin{array}{l}\text { The rheological measurements showed that the true } \\
\text { viscosity of the blends was in between the viscosity of } \\
\text { neat PP and PLA, whereas, the mechanical properties } \\
\text { clearly indicated the incompatibility between PP and } \\
\text { PLA. }\end{array}$ & Hamad et al[24]. \\
\hline 7. & $\begin{array}{l}\text { Polyblends of PP and PLA in the ratio } \\
\text { 80:20.Polypropylene-g-maleic anhydride } \\
\text { (PP-g-MAH) } \\
\text { styrene-ethylene-butylene-styrene-g-maleic } \\
\text { anhydride (SEBS-g-MAH) were used as } \\
\text { compatibilizers. }\end{array}$ & $\begin{array}{l}\text { At } 3 \mathrm{wt} \% \text { of PP-g-MAH content, the tensile strength } \\
\text { reached a maximum value and the tensile strength did } \\
\text { not change appreciably even after hydrolysis. }\end{array}$ & Yoo et al. ${ }^{[25]}$. \\
\hline 8. & $\begin{array}{l}\text { Ternary blends of PP, PLA and a } \\
\text { toughening modifier in the ratio 60:30:10 } \\
\text { PP-g-MAH and polyethylene-g- glycidyl } \\
\text { methacrylate (PE-g-GMA) and a hybrid } \\
\text { compatibilizer composed of these two were } \\
\text { incorporated into the ternary blends in } \\
\text { various ratios. }\end{array}$ & $\begin{array}{l}3 \mathrm{wt} \% \text { of the hybrid compatibilizer enhanced the } \\
\text { mechanical properties of the ternary blend before and } \\
\text { after hydrolysis. }\end{array}$ & Lee et al. ${ }^{[26]}$. \\
\hline 9. & $\begin{array}{l}\text { The effectiveness of ethylene-glycidyl } \\
\text { methacrylate-methyl acrylate terpolymer } \\
\text { (PEGMMA) as a reactive compatibilizer } \\
\text { for PLA and PP blends (in the ratio 90:10) }\end{array}$ & $\begin{array}{l}\text { This compatibilization strategy resulted in reduced } \\
\text { interfacial tension, enhancement of tensile toughness } \\
\text { and elongation at break of the resulting polyblend } \\
\text { system }\end{array}$ & $\mathrm{Xu}$ et al..$^{[27]}$. \\
\hline
\end{tabular}




\begin{tabular}{|c|c|c|c|}
\hline 10. & $\begin{array}{l}\text { Investigation of the isothermal } \\
\text { crystallisation process of PLA and } \\
\text { PP blends with and without MA-g-PP }\end{array}$ & $\begin{array}{l}\text { Blending PLA with PP resulted in a reduction in the } \\
\text { size of spherulites and the presence of MA-g-PP } \\
\text { in blends of PLA with PP promoted the growth of } \\
\text { spherulites during the crystallisation process. }\end{array}$ & Bai et al. ${ }^{[28]}$. \\
\hline 11. & $\begin{array}{l}\text { The effect of ethylene-butyl acrylate } \\
\text { glycidyl methacrylate terpolymer } \\
\text { (EBA-GMA) as a compatibilizer } \\
\text { for 70:30 blend of PLA and PP }\end{array}$ & $\begin{array}{l}\text { Based on the mechanical properties, it was shown that } \\
\text { at } 2.5 \mathrm{wt} \% \text { of EBA-GMA, the tensile strength of } \\
\text { the blend reached a maximum, whereas, the impact } \\
\text { strength showed a steady increase with an increase in } \\
\text { compatibilizer content. }\end{array}$ & Kang et al ${ }^{[29]}$. \\
\hline 12. & $\begin{array}{l}\text { Preparation of natural-flour-filled } \\
\text { PP/PLA bio-composites. Bamboo flour and } \\
\text { wood flour were used as the reinforcing } \\
\text { filler. Modifications of these natural flours } \\
\text { were carried out by treating them with } \\
\text { maleic anhydride-grafted PP and acrylic } \\
\text { acid-grafted PP. }\end{array}$ & $\begin{array}{l}\text { Tensile and flexural strengths of biocomposites were } \\
\text { found to improve as a result of the modification. }\end{array}$ & Kim et al..$^{[30]}$ \\
\hline 13. & $\begin{array}{l}\text { Oat hull fibre as a reinforcement for } \\
\text { PP/PLA based biocomposites. PP/PLA } \\
(90 / 10) \text { blend reinforced with } 30 \mathrm{wt} \% \text { oat } \\
\text { hull. }\end{array}$ & $\begin{array}{l}\text { Investigated the effect of ethylene propylene-g-maleic } \\
\text { anhydride (EP-g-Ma) as a compatibilizer for } \\
\text { this biocomposite. }\end{array}$ & Reddy et al..$^{[31]}$. \\
\hline 14. & $\begin{array}{l}\text { PLA/PP blends compatibilized by four } \\
\text { different grafted polymers and } \\
\text { subsequently prepared } \\
\text { nanocomposites with Sepiolite. }\end{array}$ & $\begin{array}{l}\text { The blend containing grafted metallocenepolyethene as } \\
\text { the compatibilizer exhibited the highest tensile } \\
\text { toughness. Incorporation of Sepiolite into the } \\
\text { compatibilized blend resulted in improvement in } \\
\text { mechanical properties, complex viscosity and storage } \\
\text { modulus compared with similar nanocomposites } \\
\text { containing only PLA as a matrix. }\end{array}$ & Nunez et al..$^{[32]}$ \\
\hline 15. & $\begin{array}{l}\text { PP/PLA blends }(80 / 20) \text { compatibilized by } \\
\text { maleic anhydride-grafted PP and } \\
\text { subsequent preparation of their } \\
\text { nanocomposites with Halloysite nanotubes. }\end{array}$ & $\begin{array}{l}\text { Dielectric analysis showed that consistent properties } \\
\text { were shown by addition of } 6 \mathrm{wt} \% \text { of HNT to the } \\
\text { compatibilized base blend, similar to static and } \\
\text { dynamic mechanical properties }\end{array}$ & Rajan et al..$^{[36,37]}$ \\
\hline 16. & $\begin{array}{l}\text { Ternary blend of PLA, liquid natural rubber } \\
\text { (LNR) and linear low density polyethylene } \\
\text { (LLDPE). }\end{array}$ & $\begin{array}{l}\text { LNR acted as an effective compatibilizer for PLA and } \\
\text { LLDPE and resulted in improved mechanical and } \\
\text { thermal properties. }\end{array}$ & Bijarimi et al..$^{[38]}$ \\
\hline
\end{tabular}

Table 2. Recent literature on blends and composites of PLA with polyolefins

\section{Blends and composites of PLA with other biodegradable materials}

The main attraction for the development of blends of PLA with other biodegradable materials is the improvement of properties of PLA without compromising the biodegradability of the resulting blend system.Blends of amorphous poly(D,L-lactic acid) (PDLLA) and crystalline poly (L-lactic acid) (PLLA) was prepared by Essawy and group ${ }^{[39]}$. The preparation was carried out in one step by melt/solid polycondensation.

\subsection{PLA with starch}

Starch is blended with PLA by various research groups in order to improve the properties of PLA. Wang et $a l^{[40]}$ prepared a blend of thermoplastic dry starch (DTPS) and PLAusing maleic anhydride (MA) as a compatibilizer in presence of dicumyl peroxide using a twin screw extruder. The blend showed an improvement 
in tensile properties and thermal degradation behavior compared with the individual components. Compatibility between starch and PLA is the major factor affecting the performance of the resulting blend. The various strategies adopted for compatibilizing starch/PLA blends were investigated by Schwachand and co-workers ${ }^{[41]}$. The different compatibilization routes: (i) formation of urethane linkages in situ; (ii) peroxide coupling between starch and PLA, and (iii) the addition of PLA-grafted amylose (A-g-PLA). The compatibilization efficiency was analyzed by measuring the mechanical and thermal properties of the blends. Based on the results, it was concluded that peroxide reticulation and the addition of a copolymercompatibilizer (PLA-grafted amylose) gave the best results. But the best compatibilization effect, with a significant increase (up to $60 \%$ ) of the tensile strength without decrease in the elongation at break, was obtained with the copolymer (A-g-PLA). The crystallization of PLA in a PLA/starch blend system was studied by Li et $a l^{[42]}$ and it was reported that crystallinity was more than $50 \%$ even at cooling rate of $80^{\circ} \mathrm{C} /$ minute. Thermal and physical degradation of PLA and its blends with starch and methylene diphenyl diisocyanate (MDI) was investigated by Acioli and co-workers ${ }^{[43]}$. Nanocomposite foams containing tapioca starch, PLA and nanoclay (Cloisite 30B) were prepared by Lee et $a l^{[44]}$ using melt intercalation technique. Nanocomposites of thermoplastic starch (TPS) and PLA with natural montmorillonite (MMT) were prepared by Arroyo and coworkers $^{[45]}$ using a twin-screw extruder and the structure-property relationship of the nanocomposite was characterized to examine the use of water to enhance clay exfoliation. It was observed that the TPS can intercalate the clay structure and the clay was preferentially located in the TPS phase or at the blend interface, leading to an improvement in tensile modulus and strength and to a reduction in fracture toughness.

In another study, TPS/PLA composites were prepared by melt blending with glycerol plasticized-starch and the isothermal crystallization kinetics of TPS/PLA composites was performed by differential scanning calorimetry (DSC) at different crystallization temperatures ${ }^{[46]}$. Avrami theory, which was applied to describe the process of isothermal crystallization, indicated that TPS acted as a nucleating agent, improving the spherulite growth rate, overall crystallization rate, and activation energy of TPS/PLA composites. Biodegradation of starch/polylactic acid/poly(hydroxyester-ether) composite bars in soil was reported by Shogren and co-workers ${ }^{[47]}$, whereas, water absorption and enzymatic degradation of poly(lactic acid)/rice starch composites were investigated by research group of $\mathrm{Yew}^{[48]}$. Recently, sea water degradation of starch/PLA composite was studied by Chen et $a l^{[49]}$. Their one year long observation showed that starch particles were lost from the composite material due to microbial action and the water was acting as a plasticizer. The observed degradation rate was very slow. Biodegradation of thermoplastic starch and its blends with PLA and polyethylenewas investigated by Li et $a l^{[50]}$.

Mechanical, thermal and biodegradability properties of PLA/modified starch blends were investigated by Gao et $a l$ and observed that addition of $15 \mathrm{wt} \%$ of modified starch resulted in a decrease of melting temperature and vicat softening temperature (VST) of the blend ${ }^{[51]}$. But similar blends of PLA with maleic anhydride grafted starch (MA-g-ST) exhibited slightly improved thermal stability. Blend of PLA with MA-g-ST showed improvementsin notched impact strength, elongation at break, and tensile strength and biodegradability compared with the unmodified blend system, which means MA-g-ST is suitable filler for improving the toughness of PLA.Blends of TPS and PLA with and without addition of glycidyl methacrylate grafted poly (ethylene octane) (GPOE) were prepared using Haake Mixer by Shi and co-workers ${ }^{[52]}$. They have investigated mechanical properties, morphology, thermal properties, water absorption and degradation of these binary and ternary blends. The blends showed excellent biodegradability too. Shin et al blended PLA with chemically modified thermoplastic starch (CMPS) using a twin-screw extruder ${ }^{[53]}$. Morphology, thermal, and mechanical properties, and biodegradability of the resulting blend was investigated. Scanning electron microscopy (SEM) and Fourier transform infrared (FTIR) studies revealed the formation of PLA-g-starch copolymersthat were formed at the interface through a transesterification reaction between PLA and CMPS, 
which improved the interfacial adhesion between the blend components. It was also observed that the biodegradability of the blends increased with increasing CMPS content. Shogren et al studied the effect of fiber orientation on the morphology and mechanical properties of PLA/starch composite filaments ${ }^{[54]}$. It was reported that tensile strength and moduli increased with increasing draw ratio but decreased with increasing starch content. They have concluded that fiber orientation greatly increased the flexibility of PLA/starch composites.

Silva et $a l^{[55]}$ incorporated wheat starch and coupling agents into poly(lactic acid) in an attempt to develop biodegradable composites. They have studied the effects of incorporating different coupling agents on the physical properties and morphology of the composites. They have observed that with the addition of $10 \%$ wheat starch and $2 \%$ MDI, blends of wheat starch/PLA exhibit tensile strength, elongation at break and impact strength properties similar to that of raw PLA and in the presence of $2 \% \mathrm{MDI}$ and $10 \%$ glycerol, blends of PLA and starch exhibits enhanced flexibility. The role of polylactide modified with reactive anhydride groups (PLA(m)) as a compatibilizer for PLA and TPS was investigated by Swierz et $a l^{[56]}$. It was reported that the blends with the compatibilizer showed improved tensile, flexural and impact properties as compared to the composites without compatibilizer. The authors reported that the interphase interactions between the hydrogen atoms of the anhydride groups in the compatibilizer and the hydroxyl groups of the starch during the reactive extrusion process are the reason behind this property enhancement. As a result of this improved interaction between the blend components, the rate of biodegradation of the blends decreases with an increase in the content of compatibilizer.

There are various strategies to improve the compatibility of PLA with various other polymers. A detailed report on these strategies are available in the recent review article authored by Zeng et al. ${ }^{[57]}$. In an attempt to increase the compatibility between PLA and starch, Wu et al ${ }^{[58]}$ added glycerine into the blend system and found that the higher the glycerine content, the better the compatibility between PLA and starch. They have also tried to crosslink the starch as a strategy to improve its compatibility with PLA and found that crosslinking greatly improved the compatibility. Yokesahachart et al ${ }^{[59]}$ modified the thermoplastic starch by adding three different types of amphiphilic molecules and prepared binary blends of modified starch with PLA. It was found that the amphiphilesimproved theprocessability, flowability and extensibility of the blends. Chabrat and co-workers ${ }^{[60]}$ plasticized wheat flour with glycerol and blended with PLA using a twin screw extruder in presence of citric acid and water. Here, citric acid acted as a compatibilizer by promoting depolymerization of both starch and PLA. Hence its dosage has to be limited to a maximum of $2 \%$, in order to avoid decrease in mechanical properties. Here the role of water is tominimize PLA depolymerization and to favor starch plasticization by citric acid and thus improve phase repartition. PLA was grafted onto starch nanoparticles by Garcia et $a l^{[61]}$. The reactions include three steps and the first step is protection of hydroxyl groups of PLA by benzoylation. This step is followed by activation of carboxyl groups using thionyl chloride and at last the modified PLA was grafted onto starch nanoparticles. The benzoylation step helped in decreasing the glass transition temperature $\left(T_{g}\right)$. The nano grafted PLA exhibited a slightly lower degradation temperature than that of pure PLA.

Poly(lactide)-graft-glycidyl methacrylate (PLA-g-GMA) copolymer was prepared by Liu et $a l^{[62]}$ by grafting GMA onto PLA using benzoyl peroxide as an initiator. PLA-g-GMA copolymer was used as acompatibilizer for PLA/starch blends. The structure and properties of PLA/starch blends with and without PLA-g-GMA copolymer were characterized by SEM, DSC, tensile test and medium resistance test. The blend system with the compatibilizer exhibited an improvement in properties. Ouyang et al[63] did pre-treatment of PLA as a method to improve the compatibility between PLA and modified starch. DSC and SEM analysis were done to find the effectiveness of pretreatment and found that the pretreatment improved the compatibility of the composites. Phetwarotai and group ${ }^{[64]}$ polylactide/gelatinized starch films by blending PLA with gelatinized starch in the presence of plasticizers and compatibilizer for improving interfacial bonding between two phases. Two types of 
starch (corn and tapioca) were used for blending with PLA. Polyethylene glycol (PEG400) and propylene glycol (PG) were used as plasticizers and methylenediphenyldiisocyanate was used as a compatibilizer. The role of poly(ethylene glycol) (PEG) as a compatibilizer for PLA/TPS blend was studied by Favaro et $a l^{[65]}$. They have reported that incorporation of PEG resulted in the increase of PLA crystallization, improved the interfacial interaction between TPS and PLA matrix, increased the impact strength of the ternary blend whereas the elastic modulus remained similar to the PLA/TPS blend. Xue et al ${ }^{[66]}$ also studied the effect of adding PEG into TPS/PLA blends. The addition of PEG resulted in lower $T_{g}$ and $T_{m}$ as well as higher MFI for the blends. It was observed that the optimum mechanical properties can be obtained for the blend system with addition of $3 \mathrm{wt} \%$ PEG. Li et a ${ }^{[67]}$ studied the non isothermal crystallization kinetics of pure PLA and TPS/PLA composites by DSC. It was observed that TPS acted as a nucleating agent and improved the crystallinity of the PLA and restricted the mobility of the PLA chains. They have also used theoretical models to describe the process of non isothermal crystallization.

The effect of nanoclay on the properties of thermoplastic Starch/PLAblends were investigated in detail by Paglicawan and group ${ }^{[68]}$. Thermoplastic starch nanocomposites with different amounts of nanoclay were prepared initially and these nanocomposites were blended with PLA in presence of maleic anhydride. The mechanical properties, thermal characteristics, microstructure and water resistance of the biodegradable nanocomposite blends were studied in detail. Biodegradable films from blends of TPS and PLA plasticized with different adipate or citrate esters were prepared by Shirai and group ${ }^{[69]}$. The films were prepared by blown film extrusion process and it was concluded that adipate esters were the most effective plasticizers based on the desired mechanical properties of the films. In another study, sheets were prepared from a blend of TPS/PLA (70:30 wt/wt) by thermopressing ${ }^{[70]}$. The sheets so prepared were coated with cross-linked chitosan by two different methods: spraying and immersion. The chitosan coating reduced the water solubility and water vapor permeability of the sheets due to the hydrophobic nature of chitosan. The coated sheets exhibited higher tensile strength than the uncoated sheets. It was concluded that coating by spraying was more effective at changing the sheet properties than coating by immersion. Xiong et al used tung oil anhydride (TOA) as a plasticizer for PLA/starch blends ${ }^{[71]}$. The addition of TOA improved the compatibility between starch and PLA and resulted in an enhancement of mechanical properties of the resulting blend. Epoxidised soybean oil (ESO) was used as a reactive compatibilizer for PLA and starch blend by Xiong et $a^{[72]}$. In the beginning, starch granules were grafted with maleic anhydride to improve its reactivity with ESO. The same research group has studied the effect of castor oil (CO) on the properties of starch/PLA blend ${ }^{[73]}$. They have tried to graft hexamethylene diisocyanate (HDI) with starch in order to accumulate the $\mathrm{CO}$ on starch surface. The accumulation of $\mathrm{CO}$ on starch greatly improved the toughness and impact strength of PLA/starch blends. Zhang et $a l^{[74]}$ investigated pressure-induced flow (PIF) processing as a method to produce a layer-like microstructure along the flow direction in PLA/starch blends. It was observed that impact and tensile strength can be improved by $200 \%$ and $40 \%$ respectively with the formation of layer-like microstructure. Composites of PLA with chitin nanowhiskers were prepared by $\operatorname{Rizvi}^{[75]}$ and group adopting melt blending technique. The incorporation of chitin resulted in a decrease in viscosity and thermal stability of the composites. The stiffness of the composites increased with an increase in chitin content. They have also prepared a porous composite structure of these composite materials by two stage batch foaming technique. The production of microfibrillated cellulose-reinforced polylactide cellular biocomposites was described by Boissard et $a^{\left[{ }^{[76]}\right.}$. They have used a wet mixing technique combined with supercritical carbon dioxide foaming to achieve the cellular composites. A comprehensive review by Koh et al. ${ }^{[77]}$ describes various toughening strategies for PLA/starch blends.

\section{PLA and natural fibers}

The incorporation of natural fiber to a PLA matrix leads to the development of a completely bio-based composite material. The study conducted by Graupner et $a l .{ }^{[78]}$ showed that incorporation of kenaf and hemp 
fibers in to PLA resulted in an improvement in tensile strength and Young's modulus values of the resulting composites. Cotton/PLA composites exhibited excellent impact properties, whereas, Lyocell/PLA composites possess improved tensile strength, Young's modulus and impact properties. Nettle fibers were used as a reinforcement for PLA by Fischer et $a l^{[79]}$. They have also compiled the effect of other fibers such as hemp, flax, jute, bamboo, kenaf and ramie as reinforcements for PLA reported by other research groups. A detailed description on the developments in the field of natural fiber reinforced PLA is available in the review article of Faruk et $a l^{[80]}$. In addition to the above mentioned fibers, they have also mentioned the use of natural and man-made cellulose fibers, coir fibers and recycled newspapers as reinforcements for PLA matrix

The influence of various natural fibers on mechanical properties and biodegradation of PLA was reviewed by Wahit and co-workers ${ }^{[81]}$. Hu et al ${ }^{[82]}$ prepared completely biodegradable composites of PLA with hemp fibers. Effect of fiber surface treatment with alkali on the properties of the composites was also investigated. It was observed that incorporation of 40 vol\% of treated fibers into PLA resulted in optimum mechanical properties of the composites. Alkali treated kenafbast fiber (KBF) was used as a reinforcement for plasticized PLA by Nor Azowa Ibrahim $^{[83]}$ and group. The effect of KBF surface treatment on the static and dynamic mechanical properties of the composites was studied in detail. It was observed that $4 \%$ of $\mathrm{NaOH}$-treated $\mathrm{KBF}$ produced composites with optimum properties. Biocomposites of PLA with banana fibers were prepared by Jandas and group ${ }^{[84]}$. The surface treatment of banana fiber was carried out by $\mathrm{NaOH}$ and various silanes and the effect of these treatments on the properties of the composites were also investigated. Jute fiber reinforced PLA was prepared by Hongwei ${ }^{[85]}$ and co-workers. They have investigated the effect of jute fiber content, processing temperature and alkali treatment on the structure and mechanical properties of jute/PLA composites. The morphology of the composite was analyzed using SEM. It was found that a fiber content of $15 \mathrm{wt} \%$ and a processing temperature of $210^{\circ} \mathrm{C}$ resulted in optimum tensile properties of the composites. Recently, Smitthipong et al. studied the role of pineapple leaf fiber (PALF) as reinforcement along with TPS and TPS/PLA blend as the matrices ${ }^{[86]}$. They have reported that the optimum fiber volume fraction of PALF for tensile strength improvement for TPS based composites is $8 \%$. They have also observed that the tensile strength of TPS withPALF/PLA composite was higher than that of the TPS/PLA blend until $60 \mathrm{wt} \%$ of TPS. Beyond this concentration, phase reversion was observed between TPS and PLA. TPS with PALF/PLA composite gave better mechanical properties and water resistance than the TPS/PLA blend. The effect of surface treatment of sisal fibers on the properties of PLA/sisal fiber composites was studied by Jiang et $a l^{[87]}$. It was found that the mechanical properties of the fibers as well as the composites were greatly influenced by the fiber surface treatment methods. Similar studies were carried out by Zou et al ${ }^{[88]}$ for short sisal fiber reinforced PLA. Akos et al ${ }^{[89,90]}$ prepared blends of poly( $\varepsilon$-caprolactone) (PCL) and PLA reinforced with Dura and Tenera palm press fibers. Dicumyl peroxide (DCP) was used as compatibilizerfor the blend system and resulted in good interfacial adhesion between the matrix and the reinforcements and thereby increased the mechanical properties of the composites. Flax fiber was used as a reinforcement for PLA by Oksman et $a l^{[91]}$. The composite was prepared by extrusion followed by compression molding. The properties of the composites were compared with that of PP/fax composites, which are widely used in making automobile components. The PLA/flax fiber composites showed $50 \%$ better strength compared with the PP counterpart. The SEM micrographs of the fractured surface showed that the fiber-matrix adhesion needs to be improved in order to improve the performance properties of PLA/natural fiber composites.

Flax fiber reinforced PLA composites were prepared by Alimuzzaman et $a l^{[92]}$. They have prepared fiber webs of flax and PLA fibers using an air-laying process. Prepregs were prepared from these fiber webs and subsequently these prepregs were converted to composites by compression molding. It was reported that mechanical properties of the composites were increased as the flax fiber content was increased. Also, the mechanical properties of the composites were decreased with an increase in the molding time and molding 
temperature. Siengchin et $a l^{[93]}$ prepared nanocomposites of PLA and woven flax fiber textiles containing nano alumina. $\mathrm{TiO}_{2}$ grafted flax fibers were used as a reinforcement for PLA by Foruzanmehr et al ${ }^{[94]}$. The modified fibers exhibited better adhesion and bonding towards PLA and thereby resulted in a threefold improvement in the impact resistance of PLA. Also the water absorption of PLA was reduced by $18 \%$ due to the incorporation of modified flax fibers. $\mathrm{Wu}$ et $a l^{[95]}$ prepared $\alpha$-cellulose short-fiber reinforced PLA composites and investigated the isothermal crystallization behavior of these composites. The crystallinity of the composites was greatly improved due to the presence of cellulose fibers. Sugarcane bagasse residues from bio-refinery processes were used as a reinforcement for the production of PLA based green composites by Wang et $a l^{[96]}$. The results proved that PLA composite with pretreated residue, in the presence of $2 \%$ coupling agent, exhibited the optimum strength properties. The effect of fiber surface treatments on the performance properties of PLA/jute fiber composites was studied by Goriparthi et al ${ }^{[97]}$. In this study, Jute fibers treated with $\mathrm{NaOH}$ solution, permanganate acetone, benzoyl peroxideacetone solution, 3-amino propyl trimethoxysilane (silane 1) and trimethoxy methyl silane (silane 2). The tensile and flexural properties of the treated composites showed improvements compared with the un treated composites. The thermal stability of the silane treated fiber composites were higher than the un-treated fiber composites whereas, all other treatments resulted in lower thermal stability for the composites. They have shown that the fiber-matrix adhesion was better in silane 2 treated fiber composites. By comparing the SEM images of the un treated composites and silane treated composites, they have shown that the silane 2 treatment improved the fiber-matrix adhesion, and thereby resulted in an improvement of the properties of the resulting composites. A recent study by Zafar et $a l^{[98]}$ describe in detail about various surface treatments and their effects on the interfacial adhesion between jute fiber and PLA.

\section{PLA with Poly (E-caprolactone)} (PCL)

Poly

(PCL) is completely biodegradable polyester. Combining the properties of PCL with PLA attracted interest of researchers in recent years. Reasonably good number of publications is available in this area ${ }^{[99-114]}$. Composites of poly( $\varepsilon$-caprolactone) (PCL) with PLA fibers were prepared byresearch group of $\mathrm{Ju}$ et $a l^{[115]}$. They have investigated the influence of PLA fibers on the crystallization, mechanical properties and enzymatic degradation of its composites with PCL. Salehiyan et al. prepared nanocomposites of PLA/PCL/montmorillonite (MMT) toughened with metallocene-catalyzed linear low-density polyethylene (mLLDPE $)^{[116]}$. It was proved that $2 \mathrm{phr}$ MMT resulted in improvement of properties owing to the intercalated structure of the clays. Jiao et $a l^{[117]}$ designed a series of PCL/PLA multiblock copolymers by a two-step process and characterized. A block copolymer of poly(ethylene glycol) and poly(propylene glycol) was used as a compatibilizer for PLA/PCL blends by Chavalitpanya et $a l^{[118]}$. An 80:20 blend of PLA/PCL was prepared by melt blending and the block copolymer content was varied from 1-10 phr. The blend system was characterized in for morphology, mechanical and thermal properties. It was concluded that $7.5 \mathrm{phr}$ of block copolymer provided a notable improvement in tensile strain at break compared to that of the neat PLA/PCL blend. Gloria et al describe the use of PCL/PLA blends as scaffolds for bone tissue regeneration ${ }^{[119]}$. The effect of MMT on the non-linear viscoelastic properties of PLA/PCL blends was investigated by Salehiyan et $a l^{[120]}$. Finotti et $a l^{[121]}$ investigated the use of two different compatibilizers for immiscible PLA/PCL blends. The compatibilizer-1 was prepared from $\epsilon$-caprolactone and 1,4butanediol and compatibilizer-2 was based on $\epsilon$-caprolactone and an aliphatic polycarbonate. The compatibilization resulted in a marked improvement in elongation at break of the immiscible blends in comparison with the uncompatibilized blend. It was also shown that the melting temperature of PLA was not affected by the chemical structure of the compatibilizer.

\section{PLA with Poly hydroxy butyrate (PHB)}

Like PLA, PHB also belongs to the family of biodegradable polyesters and finds its application in 
various areas due to its biodegradability, biocompatibility and sustainability. It is reported that both PLA and PHB are brittle at room temperature and process poor processing properties ${ }^{[122]}$. As part of improving their mechanical properties and processing characteristics, several strategies have been tried by researchers, and blending PLA with PHB is one among them. Blending of PLA with PHB has been carried out by several research groups ${ }^{[122-132]}$. These studies proved that the miscibility between PLA and PHB depends on the molecular weight of the minor component in the blend system. In case of high molecular weight blend components, PLA is immiscible with PHB in all compositions. Also it was concluded that the mechanical properties of the blends are intermediate between those of the individual blend components. The effect of processing conditions on the miscibility, crystallization, melting behavior and morphology of blends of PHB and PLA with and without poly(vinyl acetate) (PVAc) was studied by El-Hadi ${ }^{[133]}$. The results showed that PVAc can be used as an effective compatibilizer for immiscible polymer blends of PHB and PLA. Morphology, thermal properties, mechanical properties, and biodegradation behavior of PLA/PHB blends were investigated by Zhang et $a l^{[134]}$. The results showed that blending PHB with PLA is a cost effective method to improve the mechanical properties of PLA as the $75 / 25$ blend of PLA/PHB showed significant improvement in mechanical properties compared with pure PLA. The authors correlate this to the observation that finely dispersed PHB crystals acted as a filler and nucleating agent in PLA. A polyester plasticizer was used for PLA/PHB blend by Abdelwahab et $a l^{[135]}$ and the blend system was characterized by TGA, DSC, XRD, SEM, mechanical testing and biodegradation studies. The rheological properties and the morphology of PLA/poly(hydroxybutyrate-co-hydroxyvalerate)

(PHBV) blends were studied by Gerard et al ${ }^{[136]}$. Zhao et al. also ${ }^{[137]}$ blended PHBV with PLA. They have also prepared PLA/PHBV/clay nanocomposites and applied conventional and microcellular injection-molding processes to produce solid and microcellular specimens. Bartczak et $a l^{[138]}$ prepared blends of Poly(lactide) and amorphous poly ([R,S]-3-hydroxy butyrate) for packaging applications and characterized by DSC, TGA,
SEM, WAXS, DMTA and tensile tests. The effects of PHB and talc on the non isothermal cold crystallization kinetics of PLA were investigated by Tri et $a l^{[139]}$. They have reported a synergistic nucleating effect of PHB and talc on isothermal crystallization of PLA from the melt. The effect of plasticizer triacetine on the structure and properties of a polymer blend of PLA and PHB ( $85: 15$ blend) was investigated by Baran et al ${ }^{[140]}$ using high - resolution solid - state ${ }^{13} \mathrm{C}$ nuclear magnetic resonance spectra and ${ }^{13} \mathrm{C}$ spin-lattice relaxation times $\mathrm{T}_{1}\left({ }^{13} \mathrm{C}\right)$.

\section{PLA with Polyvinyl alcohol (PVOH)}

Polyvinyl alcohol (PVOH) is a water soluble and biodegradable synthetic polymer. Melt blending of PLA with PVOH can give rise to a partially miscible biodegradable blend system with improved flexibility than virgin $\mathrm{PLA}^{[141]}$. However, solution blending of PVOH with PLA leads to an immiscible blend when the PLA content in the blend system is more than $60 \mathrm{wt}^{\mathrm{\%}}{ }^{[142,143]}$. Molecular modeling simulations and thermodynamic approaches were utilized for predicting the compatibility of PLA/PVOH blend system by Jawalkar et al. ${ }^{[144]}$. Enzymatic and non-enzymatic hydrolysis of blends of PLA and PVOH were investigated by Tsuji et al ${ }^{[145]}$. Use of PVOH as a compatibilizer for starch/PLA blend system was investigated by Tianyi et $a l^{[146]}$. It was observed that above $30 \mathrm{wt} \%$, PVOH formed a continuous phase with starch. The optimum tensile strength of starch/PLA blends was obtained at a PVOH addition of $40 \mathrm{wt} \%$. 70/30 blends of PVOH and PLA were melt spun into continuous nanofibrils of average diameter $60 \mathrm{~nm}$ by An Tran et $a l^{[147]}$. The PVOH was subsequently removed from the fiber. This process produced 2D and 3D PLA textile structures suitable for scaffolds in tissue engineering. Hu et $a l^{[148]}$ prepared composite films from starch-g-PLA/PVOH. In the first step, starch-g-PLA was prepared by in situ copolymerization of starch grafted with lactic acid catalyzed with sodium hydroxide. This was then mixed with PVOH to get composite films. It was observed that the compatibility, mechanical properties and thermal stability of the composite film was improved compared with Starch/PVA film. 


\section{Conclusion}

Development of sustainable materials and products from renewable resources is one of the key focus areas of global research and development. Hence modifications of presently available commercial polymers from renewable resources become one of the hot topics of research worldwide. The main aim of preparation of polyblends and composites containing PLA is to address the current drawbacks associated with processing problems and some of the performance properties of PLA. The large volume of research works focused towards the modifications of PLA by preparing blends and composites suggest that there is still scope for further studies in this area to develop more feasible methods to address the issue.

\section{References}

1. Benninga H. A history of lactic acid making: a chapter in the history of biotechnology, Springer, 1990.

2. Prescott SC, Dunn CG. Industrial microbiology, 1949.

3. Reddy G, Altaf M, Naveena BJ,et al.Biotechnol. Adv. 2008; 26: 22.

4. Abdel-Rahman MA, Tashiro Y, Sonomoto K. Biotechnol. Adv. 2013.

5. D. Garlotta. J. Polym. Environ. 2001; 9: 63

6. Mehta R, Kumar V, Bhunia H. Journal of Macromolecular Science, Part C 2005; 45: 325.

7. Park SJ, Kim MK, Lee SY. Chem. Eng. Prog. 2012; 108: 51.

8. Lopes MS, Jardini AL, Filho RM.Procedia Engineering 2012; 42: 1402.

9. Lasprilla AJ, Martinez GA, Lunelli BH, et al. Biotechnol. Adv. 2012; 30: 321.

10. Auras RA, Lim LT, Selke SE, et al. Poly (lactic acid): synthesis, structures, properties, processing, and applications, Wiley 2011.

11. Henton DE, Gruber P, Lunt J,et al. Natural Fibers, Biopolymers, and Biocomposites, Taylor \& Francis, Boca Raton, FL, 2005; 527.

12. Drumright RE, Gruber PR, Henton DE. Adv. Mater. 2000; 12: 1841

13. Jamshidian M, Tehrany EA, Imran M, et al.Comprehensive Reviews in Food Science and Food Safety 2010; 9: 552.

14. Kawashima N, Ogawa S, Obuchi S,et al. Biopolymers Online, 2002; 251.

15. Rasal RM, Janorkar AV, Hirt DE. Prog. Polym. Sci. 2010; 35: 338.

16. Wang Y, Hillmyer MA. J. Polym. Sci., Part A: Polym. Chem. 2001; 39: 2755.

17. Anderson KS, Lim SH, Hillmyer MA. J. Appl
Polym. Sci. 2003; 89: 3757.

18. Kim Y, Choi C, Kim Y, et al.Fibers and Polymers 2004; 5: 270.

19. Reddy N, Nama D, Yang Y. Polym. Degrad. Stab. 2008; 93: 233.

20. Kaneko H, Saito J, Kawahara N,et al. Controlled/Living Radical Polymerization: Progress in Atrp, ed. K. Matyjasewski, 2009(1023): 357.

21. Choudhary P, Mohanty S, Nayak SK, et al. J. Appl. Polym. Sci. 2011; 121: 3223.

22. Donnelly Z. U.S. Patent Application 2010; 13/264,433

23. Hong CH. US Patent 8211966 B2, 2012.

24. Hamad K, Kaseem M, Deri F. Journal of Polymer Research, 2011; 18: 1799.

25. Yoo TW, Yoon HG, Choi SJ,et al.Macromolecular Research, 2010; 18: 583.

26. Lee HS, Kim JD. Polym. Compos. 2012; 33: 1154.

27. Xu Y, Loi J, Delgado P,et al.Industrial \& engineering chemistry research, 2015; 54: 6108

28. Bai ZF, Dou Q. 2015

29. Kang H, Lu X, Xu Y. Polym. Test. 2015; 43: 173.

30. Kim HS, Kim HJ. Fibers and Polymers, 2013; 14: 793.

31. Reddy JP, Misra M, Mohanty A. Advances in Mechanical Engineering, 2013.

32. Nunez K, Rosales C, Perera R, et al. Polym. Bull. 2011; 67: 1991.

33. Gallego R, López-Quintana S, Basurto F,et al. Polym. Eng. Sci., 2013.

34. Xu Y, Delgado P, Todd AD, et al. Polymer, 2016; 102: 73 .

35. Aghjeh MR, Kazerouni Y, Otadi M, et al.Composites Part B: Engineering, 2018; 137: 235.

36. Rajan KP, Al-Ghamdi A, Thomas SP, et al.J. Thermoplast. Compos. Mater.2017; 0: 0892705717734595.

37. Rajan KP, Thomas SP, Gopanna A, et al. Mater. Res. Express. 2018; 5: 085304 (https://doi.org/10.1088/2053-1591/aad1d3)

38. Bijarimi M, Ahmad S, Alam AM. Polym. Bull. 2017; 74: 3301.

39. Essawy HA, Helaly FM, Shabana MA. J. Elastomers Plast. 2007; 39: 303.

40. Wang N, Yu J, Ma X. Polym. Int. 2007; 56: 1440.

41. Schwach E, Six JL, Averous L. J. Polym. Environ. 2008; 16: 286.

42. Li H, Huneault MA. Int. Polym. Proc. 2008; 23 : 412.

43. Acioli-Moura R, Sun XS. Polymer Engineering \& Science, 2008; 48: 829

44. Lee SY, Hanna MA. Polym. Compos. 2009; 30: 665.

45. Arroyo $\mathrm{OH}$, Huneault MA, Favis BD, et al.Polym. Compos. 2010; 31: 114.

46. Cai J, Liu M, Wang L, et al.Carbohydr. Polym. 2011; 86: 941.

47. Shogren RL, Doane WM, Garlotta D, et al. Polym. 
Degrad. Stab. 2003; 79: 405.

48. Yew GH, Mohd Yusof AM, Mohd Ishak ZA,et al.Polym. Degrad. Stab. 2005; 90: 488.

49. Chen X, Wang L, Shi J, Polymers \& Polymer Composites 2011; 19: 559.

50. Li G, Sarazin P, Orts WJ, et al.Chem. Phys. 2011; 212: 1147

51. Gao H, Hu S, Su F, et al.Polym. Compos. 2011; 32: 2093.

52. Shi Q, Chen C, Gao L, et al.Polym. Degrad. Stab. 2011; 96: 175.

53. Shin BY, Jang SH, Kim BS. Polym. Eng. Sci. 2011; 51: 826.

54. Shogren RL, Selling G, Willett JL. J. Polym. Environ. 2011; 19: 329.

55. Silva KMD, Tarverdi K, Withnall R, et al.Plastics Rubber and Composites 2011; 40: 17.

56. Swierz-Motysia B, Jeziorska R, Szadkowska A,et al.Polimery 2011; 56: 271.

57. Zeng JB, Li KA, Du AK. RSC Advances, 2015; 5: 32546.

58. Wu XS. J. Polym. Environ. 2011; 19: 912.

59. Yokesahachart C, Yoksan R, Carbohydr. Polym. 2011; 83: 22 .

60. Chabrat E, Abdillahi H, Rouilly A, et al. Industrial Crops and Products, 2012; 37: 238.

61. Garcia NL, Lamanna M, D'Accorso N, et al.Polym. Degrad. Stab. 2012; 97: 2021.

62. Liu J, Jiang H, Chen L, et al. J. Polym. Environ. 2012; 20: 810.

63. Ouyang C, Wang Y, Zhao N, et al. Polym. Bull. 2012; 68: 2009 .

64. Phetwarotai W, Potiyaraj P, Aht-Ong D. J. Appl. Polym. Sci. 2012; 126: E162.

65. Favaro Ferrarezi MM, Taipina MDO, Escobar da Silva LC,et al. J. Polym. Environ. 2013; 21: 151.

66. Xue P, Wang K, Jia M,et al. Journal of Wuhan University of Technology-Materials Science Edition, 2013; 28: 157.

67. Li S, Xiong Z, Fei P,et al. J. Appl. Polym. Sci. 2013; 129: 3566.

68. Paglicawan MA, Basilia BA, Navarro MTV,et al. Journal of Biobased Materials and Bioenergy, 2013; 7: 102 .

69. Shirai MA, Grossmann MVE, Mali S,et al.Polym. 2013; 92: 19.

70. Soares FC, Yamashita F, Mueller CMO, et al.Polym. Test. 2013; 32: 94

71. Xiong Z, Li C, Ma S,et al. Carbohydr. Polym. 2013; 95: 77.

72. Xiong Z, Yang Y, Feng J, et al.Carbohydr. Polym. 2013; 92: 810.

73. Xiong Z, Zhang L, Ma S, et al. Carbohydr. Polym. 2013; 94: 235.

74. Zhang S, Feng X, Zhu S,et al. Mater. Lett. 2013; 98 : 238.

75. Rizvi R, Cochrane B, Naguib H, et al.Journal of Cellular Plastics, 2011; 47: 283.

76. Boissard CI, Bourban PE, Plummer CJG,et al.
Journal of Cellular Plastics, 2012; 48: 445.

77. Koh JJ, Zhang X, He C. Int. J. Biol. Macromol. 2018; 109: 99.

78. Graupner N, Herrmann AS, Müssig J. Composites Part A: Applied Science and Manufacturing, 2009; 40: 810.

79. Fischer H, Werwein E, Graupner N. J. Compos. Mater. 2012; 0021998311435676.

80. Faruk O, Bledzki AK, Fink HP,et al.Prog. Polym. Sci. 2012; 37: 1552.

81. Wahit MU, Akos NI, Laftah WA. Polym. Compos. 2012; 33: 1045.

82. Hu R, Lim JK. J. Compos. Mater. 2007; 41: 1655.

83. Ibrahim NA, Yunus WMZW, Othman M,et al. J. Reinf. Plast. Compos. 2011; 30: 381.

84. Jandas PJ, Mohanty S, Nayak SK, et al. Polym. Compos. 2011; 32: 1689.

85. Ma HW, Joo CW. J. Compos. Mater. 2011; 45: 1451.

86. Smitthipong W, Tantatherdtam R, Chollakup R. J. Thermoplast. Compos. Mater.2013.

87. Jiang A, Xi J, Wu H. J. Reinf. Plast. Compos. 2012; 31: 621 .

88. Zou H, Wang L, Gan H,et al. Polym. Compos. 2012; 33: 1659 .

89. Akos NI, Wahit MU, Mohamed R,et al.Polym. Compos. 2013; 34: 763.

90. Akos NI, Wahit MU, Mohamed R,et al. Compos. Interfaces, 2013.

91. Oksman K, Skrifvars M, Selin JF. Compos. Sci. Technol. 2003; 63: 1317.

92. Alimuzzaman S, Gong RH, Akonda M. Polym. Compos.2013.

93. Siengchin S, Pohl T, Medina L, et al. J. Reinf. Plast. Compos. 2013; 32: 23.

94. Foruzanmehr M, Vuillaume PY, Elkoun S,et al. Materials \& Design, 2016; 106: 295.

95. Wu JH, Kuo MC, Chen CW,et al.J. Appl. Polym. Sci. 2013; 129: 3007.

96. Wang L, Tong Z, Ingram LO,et al. J. Polym. Environ. 2013: 1.

97. Goriparthi BK, Suman K, Rao NM. Composites Part A: Applied Science and Manufacturing, 2012; 43: 1800 .

98. Zafar MT, Maiti SN, Ghosh AK. Fibers and Polymers, 2016; 17: 266

99. Harada M, Iida K, Okamoto K, et al. Polymer Engineering \& Science, 2008; 48: 1359.

100. Ren J, Yu T, Li H,et al. Polym. Compos. 2008; 29: 1145 .

101. Wang L, Ma W, Gross RA,et al. Polym. Degrad. Stab. 1998; 59: 161.

102. Wu D, Lin D, Zhang J,et al.Macromol. Chem. Phys. 2011; 212: 613 .

103. Takayama T, Todo M, Tsuji H. Journal of the Mechanical Behavior of Biomedical Materials, 2011; 4: 255.

104. Takayama T, Todo M, Arakawa K,et al. Nippon Kikai Gakkai Ronbunshu A Hen(Transactions of the 
Japan Society of Mechanical Engineers Part A)(Japan), 2006; 18: 173.

105. Semba T, Kitagawa K, Ishiaku US,et al. J. Appl. Polym. Sci. 2006; 101: 1816.

106. López-Rodríguez N, López-Arraiza A, Meaurio E,et al. Polymer Engineering \& Science, 2006; 46: 1299.

107. Grijpma DW, Zondervan GJ, Pennings AJ. Polym. Bull. 1991; 25: 327.

108. Dunnen WFA, Schakenraad JM, Zondervan GJ,et al. Journal of Materials Science: Materials in Medicine, 1993; 4: 521.

109. Hiljanen-Vainio M, Varpomaa P, Seppälä J, et al. Macromol. Chem. Phys. 1996; 197: 1503.

110. Groot JH, Zijlstra FM, Kuipers HW,et al. Biomaterials, 1997; 18: 613.

111. Deng X, Zhu Z, Xiong C, et al. J. Polym. Sci., Part A: Polym. Chem. 1997; 35: 703.

112. Huang MH, Li S, Vert M. Polymer, 2004; 45: 8675.

113. Cohn D, Hotovely Salomon A. Biomaterials, 2005; 26: 2297.

114. Sarazin P, Li G, Orts WJ, et al.Polymer, 2008; 49: 599.

115. Ju D, Han L, Li F,et al. Polym. Compos. 2013.

116. Salehiyan R, Yussuf AA, Hanani NF,et al. J. Elastomers Plast. 2013.

117. Jiao M, Yang K, Cao J,et al. Journal of Macromolecular Science, Part B, 2013.

118. Chavalitpanya K, Phattanarudee S. Energy Procedia, 2013; 34: 542.

119. Gloria A, Bártolo PJ, Patrício T. Advanced Materials Research, 2013; 683: 168.

120. Salehiyan R, Hyun K. Korean J. Chem. Eng. 2013; 30: 1013.

121. Finotti PF, Costa LC, Chinelatto MA. Effect of the Chemical Structure of Compatibilizers on the Thermal, Mechanical and Morphological Properties of Immiscible PLA/PCL Blends, 2016.

122. Park JW, Doi Y, Iwata T.Biomacromolecules, 2004; 5: 1557.

123. Blümm E, Owen AJ. Polymer, 1995; 36: 4077.

124. Koyama N, Doi Y. Can. J. Microbiol. 1995; 41: 316.

125. Zhang L, Xiong C, Deng X. Polymer, 1996; 37 : 235.

126. Koyama N, Doi Y. Polymer, 1997; 38: 1589.

127. Ohkoshi I, Abe H, Doi Y. Polymer, 2000; 41: 5985.

128. Ferreira BMP, Zavaglia CAC, Duek EAR. J. Appl. Polym. Sci. 2002; 86: 2898.

129. Focarete ML, Scandola M, Dobrzynski P, et al. Macromolecules, 2002; 35: 8472.

130. Vogel C, E. Wessel and H. W. Siesler, Biomacromolecules, 2007; 9: 523.

131. Vogel C, Siesler HW. Macromolecular Symposia, 2008; 265: 183.

132. Vogel C, Hoffmann GG, Siesler HW. Vib. Spectrosc, 2009; 49: 284.

133. El-Hadi AM. Polymer Engineering \& Science, 2011;
51: 2191

134. Zhang M, Thomas NL. Adv. Polym. Tech. 2011; 30: 67.

135. Abdelwahab MA, Flynn A, Chiou BS, et al. Polym. Degrad. Stab. 2012; 97: 1822.

136. Gerard T, Budtova T. Eur. Polym. J. 2012; 48: 1110.

137. Zhao H, Cui Z, Wang X, et al. Composites Part B: Engineering, 2013; 51: 79.

138. Bartczak Z, Galeski A, Kowalczuk M, et al.Eur. Polym. J. 2013.

139. Tri PN, Domenek S, Guinault A,et al. J. Appl. Polym. Sci. 2013; 129: 3355.

140. Baran A, Vrábel P, Olčák D, et al.J. Appl. Polym. Sci. 2018; 135.

141. Yeh JT, Yang MC, Wu CJ,et al.Polymer-Plastics Technology and Engineering, 2008; 47: 1289.

142. Shuai X, He Y, Asakawa N, et al. J. Appl. Polym. Sci. 2001; 81: 762.

143. Tsuji H, Muramatsu H. J. Appl. Polym. Sci. 2001; 81: 2151.

144. Jawalkar SS, Aminabhavi TM. Polymer, 2006; 47: 8061.

145. Tsuji H, Muramatsu H. Polym. Degrad. Stab. 2001; 71: 403.

146. Ke T, Sun X. J. Polym. Environ. 2003; 11: 7.

147. An Tran NH, Brünig H, Hinüber C,et al. Macromolecular Materials and Engineering, 2013; $\mathrm{n} / \mathrm{a}$.

148. Hu Y, Wang Q, Tang M. Carbohydr. Polym. 2013; 96: 384 . 